\title{
Numerical and experimental analysis of full scale arches reinforced with GFRP materials
}

\author{
Ismael Basilio ${ }^{1, a}$, Roberto Fedele ${ }^{2, b}$, Paulo Lourenço ${ }^{3, c}$, and Gabriele Milani ${ }^{4, d *}$ \\ ${ }^{1}$ Formerly, Department of Construction and Health, Danish Building Research Institute (SBi), \\ Aalborg University, CPH A.C. Meyers Vænge 15, 2450 Copenhagen SV, Denmark \\ ${ }^{2}$ Dept. of Civil and Environmental Engineering (DICA), Politecnico di Milano, Piazza Leonardo da \\ Vinci 32, 20133 Milan, Italy \\ ${ }^{3}$ Department of Civil Engineering, University of Minho, Campus de Azurem, Guimaraes, Portugal \\ ${ }^{4}$ Dept. of Architecture, Built Environment and Construction Engineering (ABC), Politecnico di \\ Milano, Piazza Leonardo da Vinci 32, 20133 Milan, Italy \\ aibasilios@gmail.com, ${ }^{b}$ roberto.fedele@polimi.it, ${ }^{c} p b \mid @$ civil.uminho.pt, ${ }^{d}{ }^{*}$ gabriele.milani@polimi.it \\ *Corresponding author, e-mail: milani@stru.polimi.it, gabriele.milani@polimi.it, \\ Phone: +39022399 4290 .
}

Keywords: Masonry, FRP strengthening, Masonry arches, Delamination, limit analysis, FEM.

\begin{abstract}
In this contribution, original limit analysis numerical results are presented dealing with some reinforced masonry arches tested at the University of Minho-UMinho, PT. Twelve in-scale circular masonry arches were considered, reinforced in various ways at the intrados or at the extrados. GFRP reinforcements were applied either on undamaged or on previously damaged elements, in order to assess the role of external reinforcements even in repairing interventions. The experimental results were critically discussed at the light of limit analysis predictions, based on a 3D FE heterogeneous upper bound approach. Satisfactory agreement was found between experimental evidences and the numerical results, in terms of failure mechanisms and peak load.
\end{abstract}

\section{Introduction}

During the last years, Fiber Reinforced Polymers (FRP) have being widely used not only as valuable strengthening to increase the in- and out-of-plane strength, but also to increase the load carrying capacity of arches and vaults. In fact, composite materials can be advantageously applied at the intrados or at the extrados surfaces of both flat and vaulted masonry structures, to prevent or delay collapse mechanisms and consequently increase the overall structural load bearing capacity, even under seismic actions. Nowadays, a relatively wide experimental literature dealing with masonry arches reinforced with FRP is at disposal [1]-[5], which provides interesting design information for all practitioners interested in an effective rehabilitation strategy of masonry curved structures.

From a practical point of view, a good understanding of the interface bond is a prerequisite for achieving more reliable and rational design of masonry structures reinforced by FRP composites. Although early FRP studies available in the literature were focused on concrete elements, recent contributions concerned durability of the interface bond for masonry structures, see e.g. [6][7], deepening the knowledge of such issue also for masonry.

In the present paper, the behavior of masonry arches strengthened with composite materials is investigated mainly from a numerical standpoint using limit analysis. We refer for comparison to a wide experimental campaign conducted at UMinho on several circular in-scale arches reinforced in various ways with GFRP strips. Numerically, recourse is made to a heterogeneous limit analysis FE approach to interpret the experimental data, similarly to what recently presented by one of the authors in [9]-[12]. 
As well known, limit analysis represents a valuable alternative to expensive step-by-step nonlinear FE simulations, to predict the ultimate mechanical response of masonry structures at collapse. In particular, an upper bound approach combined with a FE discretization of the actual heterogeneous microstructure provides in a rather easy way failure mechanisms and the collapse loads. A typical drawback of this approach is however the simplifying assumption of perfectly-plastic material behavior for masonry and for the FRP/masonry interface, i.e. the softening effect with consequent strain localization and possible limited ductility are neglected [12][13].

Comparisons with experimental data confirm that the present limit analysis computations are capable of well approximate both failure mechanisms and load carrying capacity of the arches. Such tool, thanks to its simplicity, turns out to be especially suitable for all the practitioners interested in a fast evaluation of the beneficial effect induced by FRP strip retrofitting.

\section{Experiments on masonry arches, a review}

In-scale models of masonry elements were used for the experimental campaign at UMinho [8], mainly to achieve a faster construction process and an easier testing setup, without any reference to similarity laws. Therefore, the results outlined and carefully validated herein cannot be directly extrapolated to real scale elements.

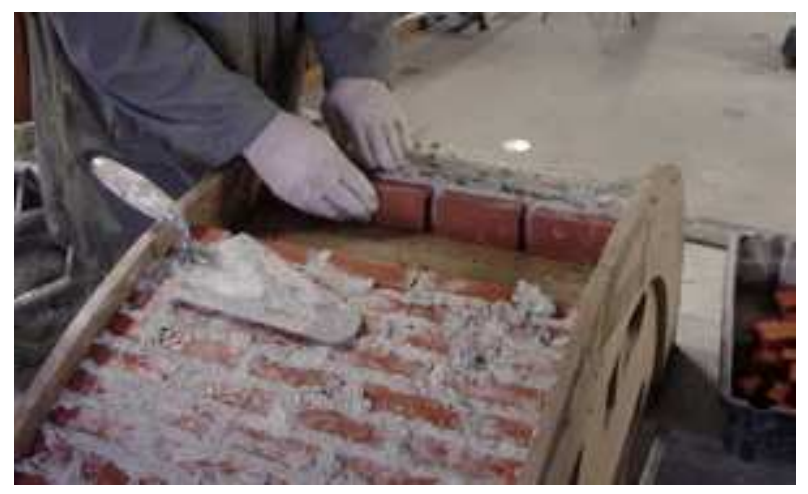

(a)

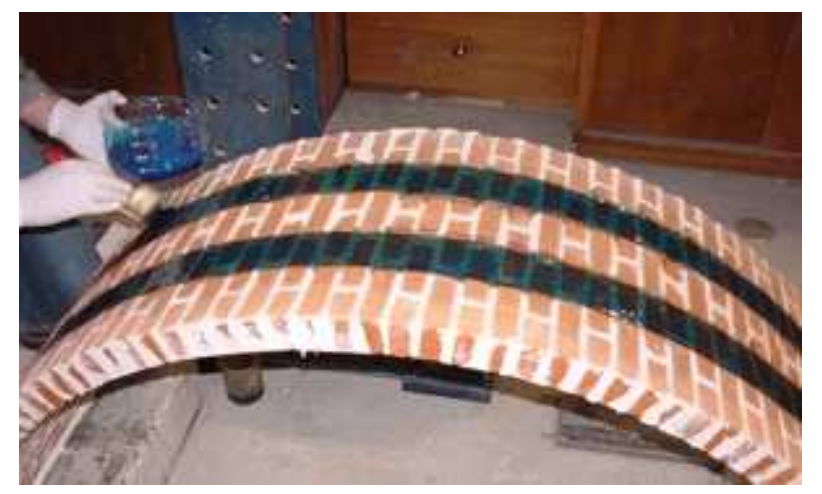

(b)

Fig. 1: Masonry arches preparation: (a) bricks assemblage near the key stone during construction and (b) finished specimen after 1 week of curing, during application of GFRP strips.

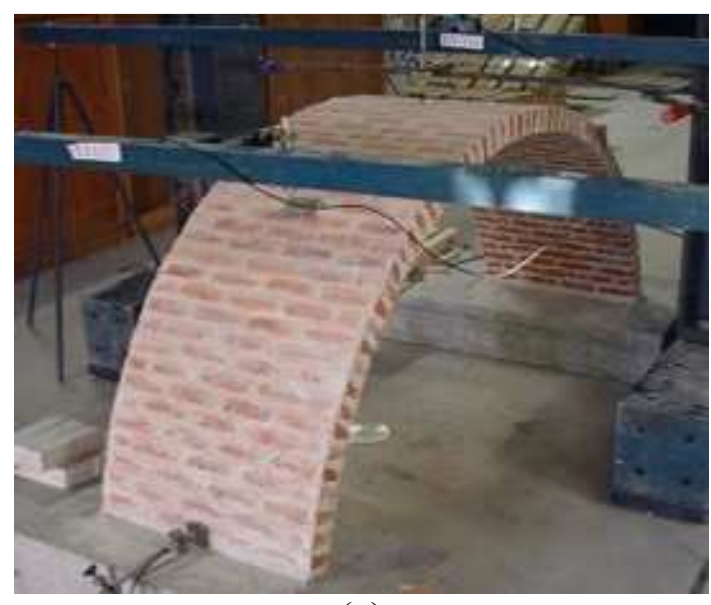

(a)

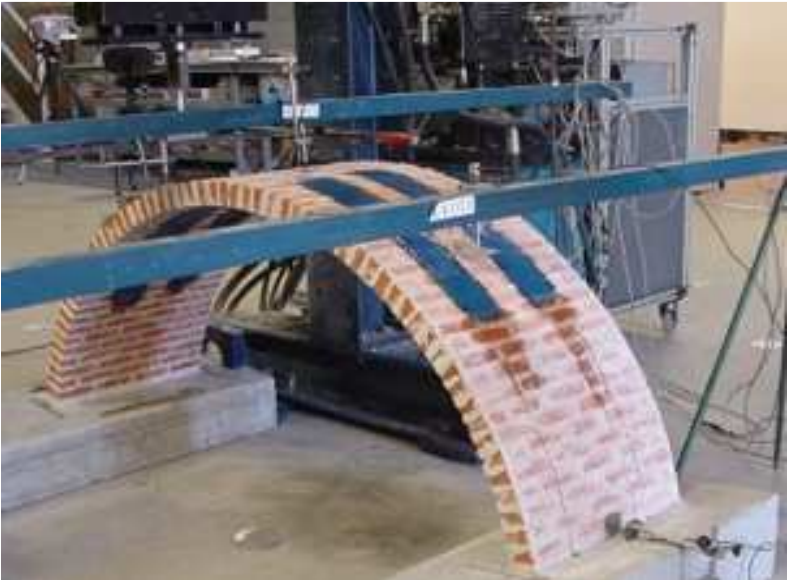

(b)

Fig. 2: Testing configurations for masonry arches: (a) typical unreinforced sample (labelled as US) and (b) localized reinforced specimen (LS), previously damaged as in (a). Refer to Table 1 for ID and GFRP width strips.

All arches were constructed over a scaffold wooden frame, keeping constant intrados mortar joint thickness of approximately $10 \mathrm{~mm}$. The construction of masonry arches was accomplished in two phases (see Fig. 1). At the beginning, the first layer of bricks was laid over the formwork, starting 
from both abutments up to the quarter perimeter of the arch. Thereafter, remaining courses were laid simultaneously from both ends in such a way that the joint thickness could be tuned to obtain a full brick at the crown, see Fig. 1-a. The protocol for the reinforcement applications required a thin putty layer applied on a cleaned surface, to subsequently prime the arch surface using MBrace Primer, rollered onto the surface and left to become tacky before socking and finalize with GFRP strips. Fig. 1-b shows the primed area. Moreover, localized reinforcements were applied on two arches already damaged (loaded up to the first hinge formation and then unloaded), constituted of symmetric parallel GFRP strips, transversely to the mortar joints at the expected hinges location. Further construction details can be found in [8], where the reader is referred to.

Table 1. Comparison between experimental and numerical (limit analysis).

\begin{tabular}{|c|c|c|c|c|c|c|c|c|}
\hline \multirow{4}{*}{$\begin{array}{c}\text { Construct } \\
\\
\text { ID }\end{array}$} & \multirow{2}{*}{\multicolumn{2}{|c|}{$\begin{array}{c}\text { GFRP } \\
\text { Reinforcement }\end{array}$}} & \multicolumn{6}{|c|}{ Results } \\
\hline & & & \multicolumn{4}{|c|}{ Experimental } & \multicolumn{2}{|c|}{ Numerical } \\
\hline & \multicolumn{2}{|c|}{$\begin{array}{l}\text { Strip width, } \\
\mathrm{w}[\mathrm{mm}]\end{array}$} & \multicolumn{2}{|c|}{$\begin{array}{l}\text { Collapsed load, } \\
\text { F }[\mathrm{kN}]\end{array}$} & \multirow{2}{*}{$\begin{array}{c}\text { Resistance } \\
\text { increase } \\
{[\%]}\end{array}$} & \multirow{2}{*}{$\begin{array}{c}\text { Sustained } \\
\text { disp } \\
{[\mathrm{mm}]}\end{array}$} & \multirow{2}{*}{$\begin{array}{c}\text { UB } \\
\text { limit } \\
\text { analysis } \\
{[\mathrm{kN}]}\end{array}$} & \multirow{2}{*}{$\begin{array}{c}\text { Error } \\
{[\%]}\end{array}$} \\
\hline & Intrados & Extrados & Max & Average ${ }^{\mathrm{II}}$ & & & & \\
\hline US-1 & - & - & 1.43 & & & & & \\
\hline US-2 & - & - & 1.92 & 1.68 & - & 0.5 & 1.88 & 11.9 \\
\hline LS-1 & \multicolumn{2}{|c|}{150.0} & 3.18 & & & & & \\
\hline LS-2 & \multicolumn{2}{|c|}{150.0} & 2.73 & 2.96 & 76 & 0.9 & 3.23 & 9.1 \\
\hline CSE-1 & - & 100.0 & 2.51 & & & & & \\
\hline CSE-2 & - & 100.0 & 3.82 & 3.17 & 89 & 15.5 & 3.68 & 16.09 \\
\hline CSE-3 & - & 160.0 & 3.62 & 344 & 105 & 288 & 401 & 1657 \\
\hline CSE-4 & - & 160.0 & 3.26 & 3.44 & 100 & 28.8 & 4.01 & 10.51 \\
\hline CSI-1 & 100.0 & - & 4.26 & & & & & \\
\hline CSI-2 & 100.0 & - & 4.63 & 4.45 & 165 & 35.9 & 4.55 & 2.3 \\
\hline${ }^{\mathrm{I}} \mathrm{CSI}-3$ & 100.0 & - & 5.41 & 41 & 174 & 227 & 480 & 6 \\
\hline${ }^{\mathrm{I}} \mathrm{CSI}-4$ & 100.0 & - & 3.81 & 4.01 & $1 / 4$ & 32.1 & 4.89 & 0.1 \\
\hline
\end{tabular}

Within the experimental campaign twelve masonry arches were built (see Fig. 2), with a semicircular shape and free span of $1.50 \mathrm{~m}$, each one constituted of 59 brick courses. Thickness of each ring was equal to the brick height, equal to $50 \mathrm{~mm}$ (thickness/span $\approx 1 / 30$ ), see Fig. 3 . All arches required two weeks of curing before testing. Four typologies of arches were considered (see Fig. 3 and Table 1):

- unreinforced, labeled as US-n ( $\mathrm{n}=1$ indicates the first sample, etc.);

- localized reinforcement applied on unreinforced tested arches, labeled as LS-n;

- continuous reinforcement at the extrados (CSE-n);

- continuous reinforcement at the intrados (CSI-n).

Synopsis in Table 1 visualizes GFRP width strips applied on each reinforced masonry arch, endowed by the experimental peak load and its limit analysis prediction. A servo-controlled testing machine was utilized, equipped with a $25 \mathrm{kN}$ cell capacity; the jack was positioned at the middle of the arch width, Fig. 2. The load was applied at the quarter span, see Fig. 3. Thanks to the very small deflection exhibited by the arches near failure, the deformation does not change significantly the position of the load, which should follow the application point when the arch deforms. Therefore, the loading tool results in an application of a horizontal component on the arches which can be neglected in the limit analysis calculations. 

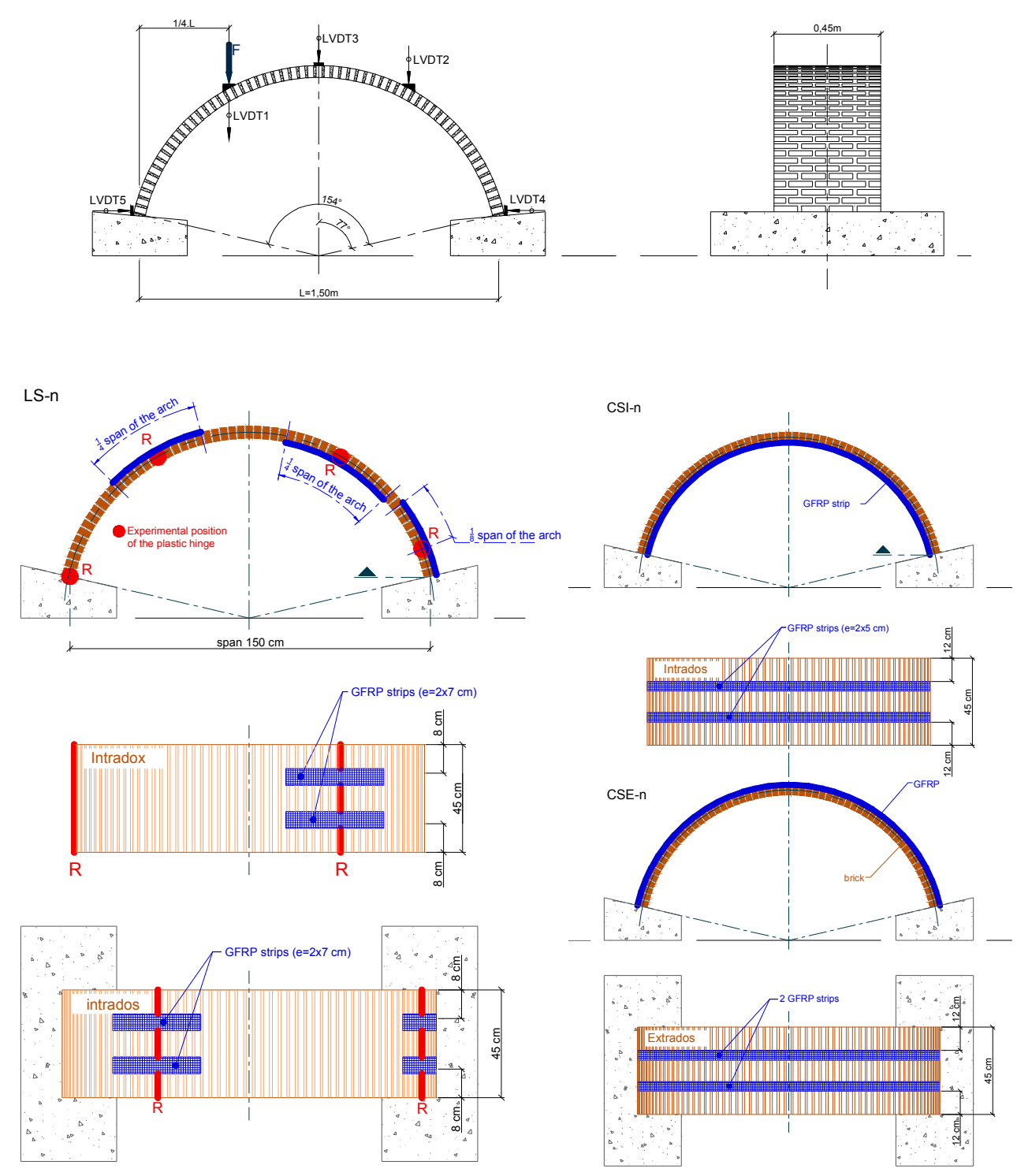

Fig. 3: Geometry and typology of tested masonry arches: with localized reinforcement after damage (LS-n), with continuous reinforcement at the extrados (CSE-n), and with continuous reinforcement at the intrados in (CSI-n).

The arches without reinforcement (US-n) exhibited a brittle collapse, with a typical four-hinge mechanism. All the tested reinforcements led to an increase of the load bearing capacity. It is worth noting that localized reinforcements (LS-n), which are typical of retrofitting interventions, partially against intuition, did not alter the original failure mechanisms observed in unreinforced elements. The reason is connected to the fact that the formation of the plastic hinges occurs always in the same position (under the load, on abutments and in an intermediate point on the opposite side of the load) and therefore the only effect that the reinforcement has is to spread a little bit the length of the plastic hinges, thus increasing the load bearing capacity.

For the masonry arches reinforced at the extrados (CSE-n), the first hinge was formed beneath the applied load, whereas the other two hinges appeared afterwards at the supports. Relative sliding along a mortar joint close to arch support was observed for this arch typology, indicating an insufficient shear resistance. Reinforcement applied at the extrados (CSE-n) provided the higher deformation capacity prior to failure.

In the masonry arches reinforced at the intrados (CSI-n) detachment of the FRP strips from the masonry substrate involved ripping of a thin layer of brick and mortar. Two of the hinges were 
formed at the lateral supports and the third hinge appeared at the extrados closely to the opposite loading side. At failure, detachment of GFRP strips from the support occurred.

\section{Limit analysis by Finite Elements}

Arches were modelled by means of the FE approach firstly proposed in [9]-[12]. Here, for the sake of conciseness, only the basic assumptions of the mathematical model are recalled, whereas the reader interested in details is referred to [10].

Basically, the model relies on a distinct representation of blocks and mortar joints. In particular, bricks are modelled by means of eight-noded elements, interacting each other through rigid-plastic interfaces. The possible presence of external reinforcement is taken into consideration by fournoded plate elements, connected to the support by a rigid plastic interface. The peak strength of such interface is assumed equal to peak delamination provided by Italian Guidelines CNR DT200 [13]. A more rigorous assessment of the delamination strength in the presence of curved substrates was presented in [14], which however provides, globally, results very near to those obtained using standard delamination formulae. A possible rupture of the strip for axial load is also allowed for at the interface between contiguous FRP elements. Strips do not contribute under compression, since a very low compression strength is assumed at the same interfaces. Under the aforementioned hypotheses, to determine failure loads and mechanisms a linear programming problem has to be solved. The linear programming problem involves very few variables, thanks to assumption of infinitely resistant brick elements. By formulae one has:

$\left\{\begin{array}{l}\min \left\{\mathbf{P}_{I}^{\text {in,ass }} \dot{\boldsymbol{\lambda}}^{I, \text { ass } T}-\mathbf{P}_{0}^{T} \mathbf{w}\right\} \\ \text { such that: }\left\{\begin{array}{l}\mathbf{A}^{e q} \mathbf{U}=\mathbf{b}^{e q} \\ \dot{\boldsymbol{\lambda}}^{I, \text { ass }} \geq \mathbf{0}\end{array}\right.\end{array}\right.$

The objective function to minimize is represented by the total internal power dissipated minus the power dissipated by external loads. In Eq. ( 1 ) symbols possess the following meaning:

- $\mathbf{U}$ denotes the vector of global unknowns and collects the velocities at element centroids, endowed by rotations of both FRP and bricks and plastic multiplier rates at the interface $\left(\dot{\lambda}^{I \text {,ass }}\right)$. Such multipliers govern the rigid perfectly-plastic response of mortar interfaces, brick-brick interfaces, FRP-FRP interfaces and masonry-FRP interfaces;

- $\quad \mathbf{A}^{e q}$ indicates the matrix of constraints and collects normalization conditions, velocity boundary conditions and constraints for plastic flow in velocity discontinuities (on FRP, mortar interfaces, brick-brick interfaces and FRP-masonry interfaces);

- $\quad \mathbf{P}_{I}^{\text {in, ass }}$ gathers different contributions to the internal dissipation of mortar, resulting from the interaction between brick and brick, FRP and FRP, FRP interfaces and the support.

The reader is referred to [9]-[12] for a critical discussion of linear programming tools apt to effectively solve Eq. ( 1 ).

Table 2. Mechanical properties adopted for the constituent materials

\begin{tabular}{|c|c|c|c|c|c|}
\hline & $f_{t}$ & $c$ & $\Phi$ & $f_{c}$ & $\Phi_{2}$ \\
\hline & $\begin{array}{c}\text { tensile strength } \\
{[\mathrm{MPa}]}\end{array}$ & $\begin{array}{c}\text { cohesion } \\
\text { [MPa] }\end{array}$ & $\begin{array}{l}\text { friction } \\
\text { angle } \\
\text { [Deg] }\end{array}$ & $\begin{array}{c}\text { compressive } \\
\text { strength } \\
{[\mathrm{MPa}]}\end{array}$ & $\begin{array}{c}\text { shape of the } \\
\text { linearized cap } \\
\text { [Deg] }\end{array}$ \\
\hline mortar & 0.18 & 0.3 & 36 & 7.8 & 45 \\
\hline $\begin{array}{c}\text { FRP-substrate } \\
\text { interface }\end{array}$ & 0.44 & 0.44 & 10 & 0.1 & 90 \\
\hline
\end{tabular}




\section{Discussion}

In the proposed limit analysis approach bricks are discretized by eight-noded elements and joints are reduced to interfaces obeying a Mohr-Coulomb failure criterion with tensile cutoff and linearized cap in compression, see [11] for details. The methodology is quite general and valid also for double curvature elements. Mechanical properties adopted for the constituent materials are summarized in Table 2.

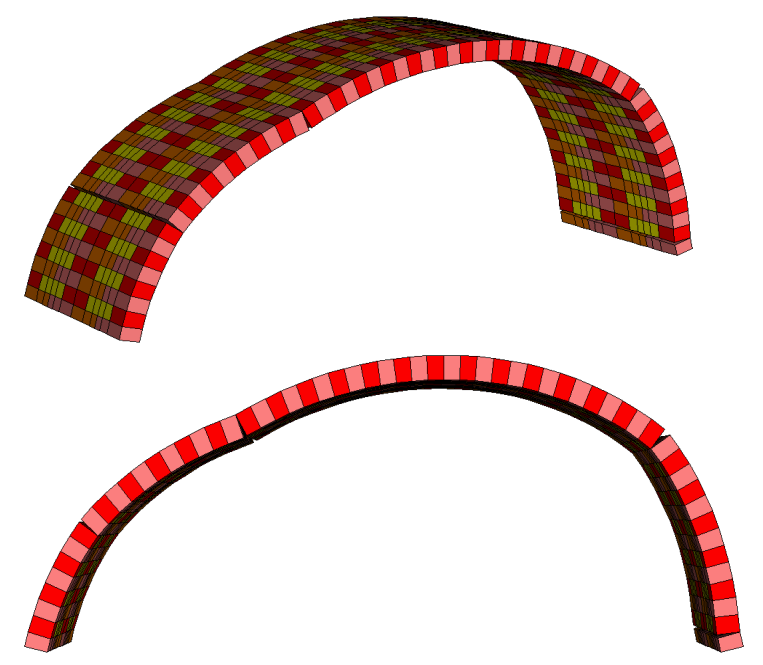

(a)

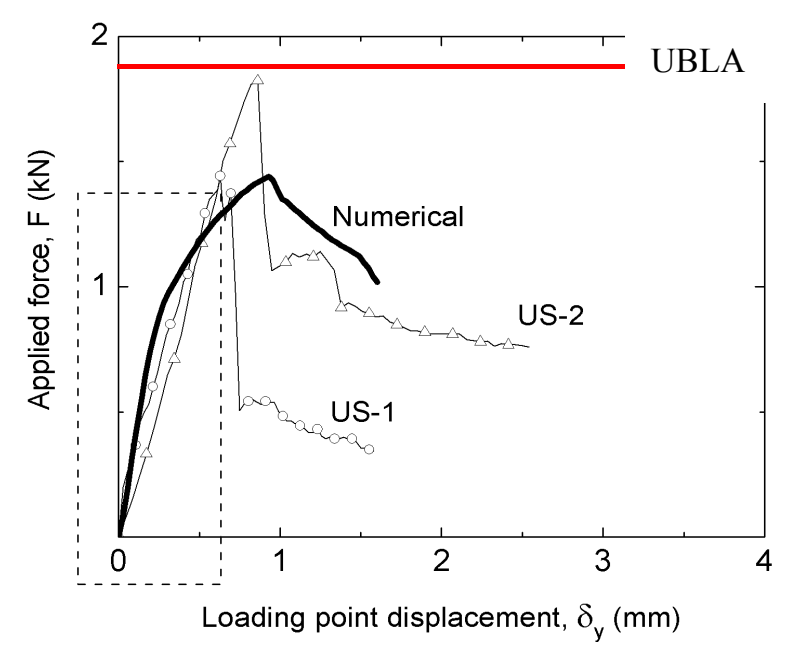

(b)

Fig. 4: Unreinforced arches (US): (a) deformed shape at collapse, limit analysis; (b) synoptic view of experimental force-displacement curves (thin curves marked by circle), overall plot provided by nonlinear FE analyses (thick curves, commercial code DIANA) and limit analysis prediction (dashed line).

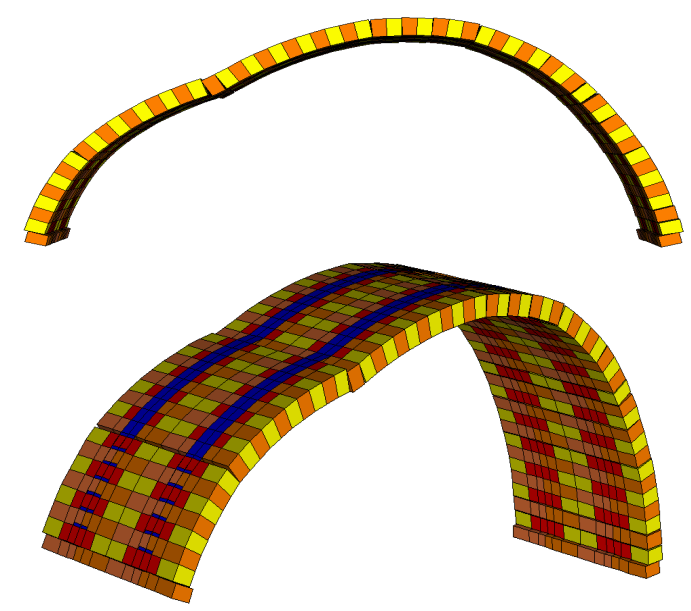

(a)

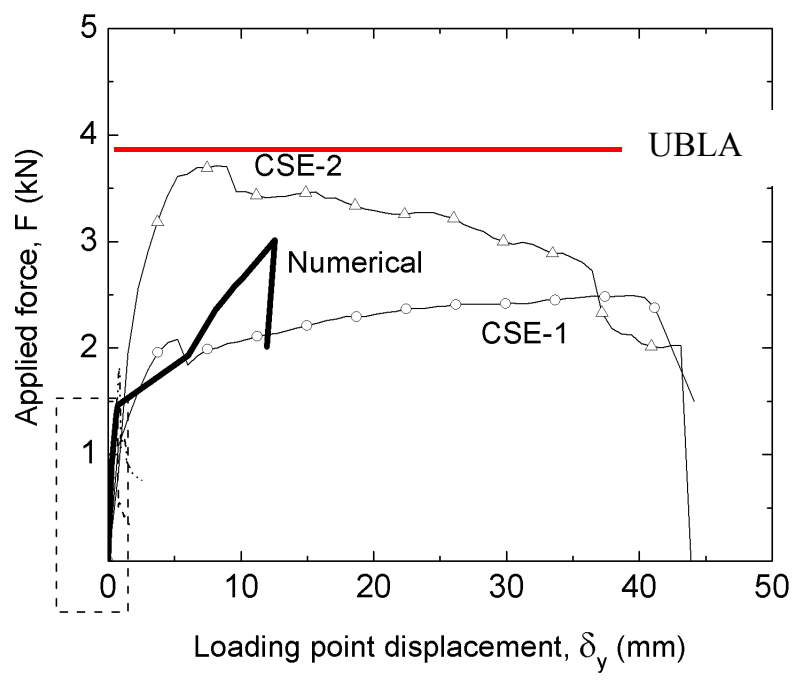

(b)

Fig. 5: CSE arch (100 mm wide reinforcement): (a) deformed shape at collapse, limit analysis; (b) synoptic view of experimental force-displacement curves (thin curve marked by circle), overall plot provided by nonlinear FE analyses (thick vurve, commercial code DIANA) and limit analysis prediction (dashed line).

In Fig. 4-a, the failure mechanism reconstructed by the present approach is represented in absence of reinforcement at the extrados. The four hinges are clearly located between contiguous bricks, forming a classic four-hinge mechanism. A comparison among the overall experimental response in 
terms of force and displacement, the numerical predictions obtained by a step-by-step FE procedure with a commercial code (DIANA) and the limit analysis results is provided in Fig. 4-b.

In Fig. 5 and Fig. 6 the same results are visualized in case of extrados (CSE specimens, width of the strips equal to $100 \mathrm{~mm}$ ) and intrados (CSI specimens, width of the strips equal to $100 \mathrm{~mm}$ ) continuous reinforcements. Further data concerning LS specimens and strips width equal to $160 \mathrm{~mm}$ are not represented herein, for the sake of brevity. However, the numerical response resulted in agreement with the experimental data, in terms of both failure mechanisms and collapse loads.

According to the results reported in Fig. 5 and Fig. 6, it is worth emphasizing that the presence of FRP reinforcements leads to markedly different failure mechanisms. In particular, the CSE samples exhibit a clear sliding on abutments (corroborated by experimental observations) and some shear sliding closely to the intermediate hinges, with localized detachment of the FRP elements under normal force. Also, the formation of the plastic hinges in masonry is not anymore clear as in the unreinforced case: this circumstance confirms the presence of complex interactions at the interface between masonry support and the FRP strips.

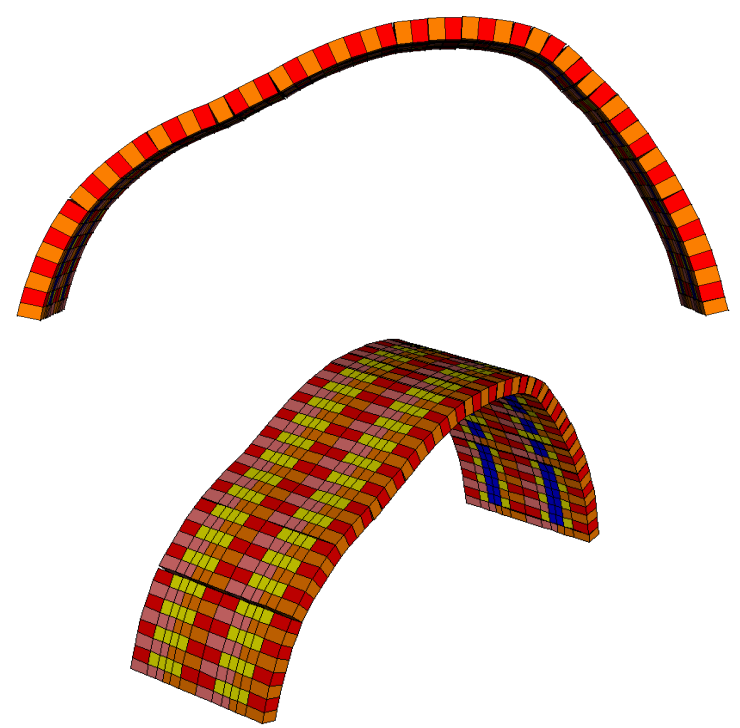

(a)

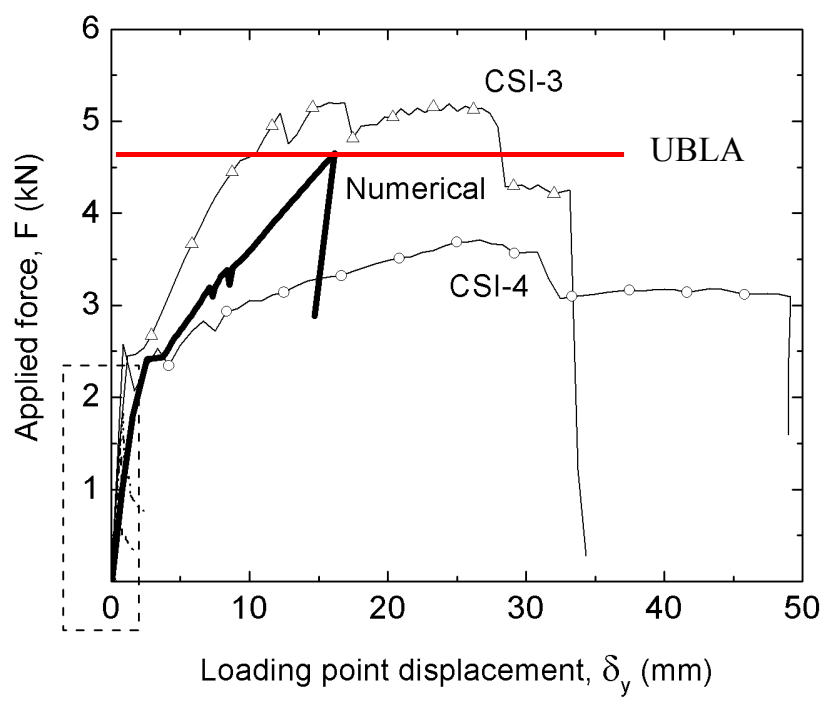

(b)

Fig. 6: CSI arch (100 mm wide reinforcement): (a) deformed shape at collapse, limit analysis; (b) synoptic view of experimental force-displacement curves (thin line marked by circle), overall plot provided by nonlinear FE analyses (thick line, commercial code DIANA) and limit analysis prediction (dashed line).

\section{Conclusions}

In this contribution, some numerical results based on a heterogeneous limit analysis code fitting results of a wide experimental campaign developed at the University of Minho [8] were presented. The main objective of the work was to have an insight into the beneficial effect induced by the introduction of GFRP strips on masonry arches, undamaged or previously damaged without reinforcement.

The numerical limit analysis tool proposed results particularly suitable for an utilization at professional level, because it requires exclusively few mechanical properties at failure (for bricks, mortar, FRP and FRP/masonry interface) and provides very quickly collapse loads and failure mechanisms.

The validation of the heterogeneous limit analysis against experimental evidences and alternative step by step FE software with softening materials addressed a good predictivity exhibited by limit analysis, with extremely reduced processing time needed.

Further developments of the present study concern the application of no-contact, full-field measurements by Digital Image Correlation (see e.g. [14]) to accurately monitor deformation fields 
over the masonry arch surface at different loading phases in newly conceived experiments. In fact surface measurements based on digital images, which are intrinsically multi-scale, are expected to provide more information to correlate the local mechanisms at the micro-scale with the overall response.

\section{References}

[1] A. Borri, G. Castori, M. Corradi. Intrados strengthening of brick masonry arches with composite materials. Composites Part B: Engineering, 42(5) (2011), 1164-1172.

[2] I. Cancelliere, M. Imbimbo, E. Sacco. Experimental tests and numerical modeling of reinforced masonry arches. Engineering Structures 32(3) (2010), 776-792.

[3] P. Foraboschi. Strengthening of masonry arches with fiber-reinforced polymer strips. J Compos Constr ASCE (2004), 191-201.

[4] M.R. Valluzzi, M. Valdemarca, C. Modena. Behavior of brick masonry vaults strengthened by FRP laminates. J Compos Constr ASCE (2001), 163-169.

[5] S. Briccoli Bati, M. Rapallini, A. Tralli. Behavior of fiber reinforced barrel vaults under reversed cycles of spring settlements. In: Proceeding of the first national conference on mechanics of masonry structures strengthened with FRP materials: Modelling, testing, design, control (2000), 65-74

[6] R. Fedele, G. Milani, Assessment of bonding stresses between FRP sheets and masonry prisms during delamination tests, Composites Part B:Engineering, 43 (2012), 1999-2011.

[7] R. Fedele, G. Milani, Three dimensional effects induced by FRP-from masonry delamination, Composite Structures, 93(7) (2011), 1819-1831.

[8] D.V. Oliveira, I. Basilio, P.B. Lourenço, Experimental Behavior of FRP Strengthened Masonry Arches, Jornal of Composites and Constructions, 14, (2010), 312-322.

[9] E. Milani, G. Milani, A. Tralli, Upper Bound limit analysis model for FRP-reinforced masonry curved structures. Part II: structural analyses. Computers \& Structures, 87 (23-24), (2009), 1534-1558.

[10] G. Milani, 3D FE limit analysis model for multi-layer masonry structures reinforced with FRP strips. International Journal of Mechanical Science 52 (2010), 784-803.

[11]G. Milani, P.B. Lourenço, A. Tralli, Homogenised limit analysis of masonry walls. Part I: failure surfaces, Computers \& Structures 84(3-4) (2006), 166-80.

[12]G. Milani, P.B. Lourenço, Simple homogenized model for the non-linear analysis of FRP strengthened masonry structures. Part I: theory, Journal of Engineering Mechanics ASCE, 139 (1), (2013), 59-76.

[13]CNR-DT-200 R1. Istruzioni per la Progettazione, l'Esecuzione ed il Controllo di Interventi di Consolidamento Statico mediante l'utilizzo di Compositi Fibrorinforzati. Consiglio Nazionale delle Ricerche, Rome, Italy (2012).

[14]I. Basilio, R. Fedele, P.B. Lourenço, G. Milani, Assessment of curved FRP-reinforced masonry prisms: experiments and modeling, Construction and Building Materials 51C (2014), 492-505. 